\title{
TOMADA DE DEPOIMENTO PESSOAL DE ENFERMEIRAS HOSPITALARES DA DÉCADA DE 50: SUBSÍDIOS PARA A COMPREENSÃO DA ENFERMAGEM ATUAL
}

\author{
Edna Paciência Vietta * \\ Marilene da Fonseca Magalhães ** \\ Luciana Villela Bueno ** \\ Anália Ribeiro Heck ${ }^{\star *}$
}

\begin{abstract}
Este estudo é parte de um projeto mais amplo que visa resgatar aspectos significativos relacionados à e evolução da assistência de enfermagem nas décadas de 50 a 90. Este resgate é feito através da técnica de depoimentos orais de enfermeiros em exercício e aposentados, no contexto de um Hospital Escola de Interior Paulista. O presente estudo particulariza os resultados obtidos, referentes à década de 50. Como resultado evidencia-se o esforço empreendido pelas enfermeiras na luta pelo reconhecimento e prestígio da profissão; as transformações intensas e profundas relacionadas aos novos papéis da enfermeira enquanto líder da equipe de membro da equipe técnica.
\end{abstract}

UNITERMOS: evolução de enfermagem, década de 50, assistência hospitalar

\section{INTRODUÇÃO}

A importância do retorno aos acontecimentos passados ou retrospectiva histórica de uma profissão se constitui no recurso apropriado quando se busca compreender o grau de sua evolução. Esta perspectiva favorece ainda uma análise efetiva do estágio atual de seu desenvolvimento e uma idéia concreta de seu potencial futuro.

*Professora Titular do Departamento de Enfermagem Psiquiátrica e Ciências Humanas da Escola de Enfermagem de Ribeirão Preto da Universidade de São Paulo.

${ }^{*}$ Colaboradoras - Bolsistas CNPq 
A trajetória percorrida pela enfermagem até a conquista de seu status profissional e daí aos dias de hoje, está permeado por muitos acontecimentos decisivos e determinantes de sua evolução, muito deles não registrados, havendo grande vazios de informação. Muitos trechos dessa jornada certamente nunca serão totalmente resgatados ou refeitos seja por ausência de anotações e registros seja por destruição, perda, descuido ou descaso, seja ainda por não se poder mais tornar vivas as memórias, quando muitos atores desta história já saíram de cena.

Parece ainda comum mesmo em áreas mais privilegiadas por acervos históricos o fato da necessidade de complementação de dados e informações. Diante de tal problemática os cientistas sociais têm buscado alternativas de resgate de fatos e acontecimentos significativos para várias áreas do conhecimento. Dentre estas possibilidades aparece a reutilização da técnica da História, relato ou depoimento oral, obtido através de memórias vivas. Este recurso se mostra útil em registrar o que ainda não se cristalizou em documentação escrita, o não conservado, o que desaparece se não for anotado, o que se pede por não estar sistematizado, as vivências mais que o conhecimento, servindo, pois para captar o não explícito, quem sabe o mesmo o indizível.

QUEIROZ (1988) esclarece que a utilização da técnica de depoimento oral teve início ainda no começo do século até o início dos anos 50, o tendo sido amplamente utilizado por sociólogos como W.I.Thomaz (1863-1947) e F. Znaniecki (1882-1958) em suas pesquisas conjuntas, datadas de 1918-1920 ou ainda JOHN DÓLAR (1900) que pretendeu traçar-Ihe regras de aplicação. Foi ainda utilizada por antropólogos do porte de Franco Boas (1858-1942) e muitos outros estudiosos.

Com o desenvolvimento das pedras e estatísticas na década de 40 até a época da editora ou depoimento oral foi relegada a segundo plano. A técnica de amostragem com aplicação de questionários tomou vulto parecendo mais apropriado no contexto e à crença no cientificismo, como forma de obtenção de dados inquestionavelmente objetivos.

A rigidez desta postura foi cedendo pouco a pouco até se dar conta de que valores e emoções permaneciam escondidos nos próprios dados estatísticos já que a formulação das perguntas estavam ligadas à maneira de pensar e sentir do pesquisador, transpondo para os dados de perigosa, por quanto invisível, sua própria percepção e preconceitos (QUEIROZ, 1988).

Ao buscamos meios para proceder o levantamento de dados se significativos para a compreensão da história da assistência de enfermagem hospitalar nos demos conta da riqueza e aplicabilidade da utilização da referida técnica na captação do resgate de vivência nem sempre tem sido registrada, não obstante o reconhecimento de seu valor inestimável por parte dos docentes e demais pesquisadores.

Sabe-se que a maior produção científica darem tem sido desenvolvida por pesquisadores docentes, sendo que só nos últimos anos os enfermeiros do serviço têm 
começado a se engajar, ainda que de forma restrita, no campo da pesquisa.

Devemos reconhecer ainda há urgência em se desenvolver trabalhos nesta orientação uma vez não se é desconhecido o fato de que um importante contingente de enfermeiros, sobretudo os mais antigos e experientes e estão se aposentando, alguns poucos que permanecem em exercício e estão aguardando suas aposentadoria. Desse modo, tomamos a iniciativa através do presente e estudo de proceder a tomada de depoimentos oral de seus enfermeiros, ainda que, numa amostra representativa pequena (o que é permitido pela telefônica, conforme explicitado a metodologia do presente estudo) buscando resgatar aspecto relevante da evolução da assistência hospitalar.

Dessa forma buscaremos inicialmente captar uma visão panorâmica dos acontecimentos significativos da década de 50 através da Literatura e especializada, sobretudo a REVISTA BRASILEIRA DE ENFERMAGEM e documentos de eventos e reuniões importantes e decisivas para a abolição. Esta retrospectiva nos dará a familiaridade com as características do período, orientando-nos quanto à condução na tomada os depoimentos.

O presente estudo será apenas parte de um estudo mais abrangente que se pretende seja conduzido dentro da mesma metodologia para as décadas que subseqüentes.

\section{REVISÃO DA LITERATURA}

O final da década de 40, caracterizou-se por uma preocupação crescente com a continuidade do cuidado ao paciente tendo em vista o resultado de lutas no da classe por redução honra da jornada de trabalho que passou de 12 para 8 horas. A tendência da instituição era a de que o paciente poderia ser cuidado por uma única enfermeira ao invés por um grupo delas, cada qual executando uma tarefa. Esta perspectiva provocou o surgimento de outras modalidades de assistência, ou seja: o modelo de assistência em grupo assim uma enfermeira poderia prestar um nível melhor de assistência e cuidado para não pequeno grupo de pacientes (de 4 a 6). Percebe-se nesta proposta uma grande influência da filosofia funcional Porto a enfermeira chefe, permanecia soberano no sentido de que era ela mesma que designava os grupos de pacientes o nível d cuidado os que deveria ser mantido. Praça o minas continua alvo ainda a representar um aspecto importante da assistência de enfermagem nesta década e o processo e comunicação de enfermagem e centralizado na enfermeira chefe.

Progressivamente este modelo foi se transformando, no sentido de atribuir às enfermeiras a responsabilidade por um número de pacientes, cuja seleção era feita de acordo com a severidade de Uchoa doença, ou de acordo com a patologia. Assim a enfermeira se encarregava dos pacientes mais graves cujo cuidado necessitasse da 
utilização de técnicas específicas e mais complexas. Conseqüentemente, ênfase da assistência orientada para tarefas foi sendo desestimulada. A enfermeira passou a responsabilizar-se pelos seus próprios registros e relatórios, e a comunicar-se diretamente com o médico. A finalidade e explicita da introdução deste modelo, conhecido por modelo de assistência individualizada foi a de otimizar as habilidades talentos da enfermeira e melhorara qualidade do cuidado prestado.

Adentrando a década de 50 importantes acontecimentos ocorreram com repercussão nos vários setores da sociedade, marcando o início de Grande profundo mudanças no setor saúde com duas transformações para a prática da enfermagem.

A modernização impulsionou, entre outras coisas, a melhoria dos padrões educacionais, a difusão da consciência política, a participação ativa da mulher da sociedade, a tendência a especialização, a divisão social do trabalho, dando margem a reestruturação das profissões, sobretudo aquelas de conotação profissionalizantes.

A Revolução industrial nos fins do século XVIII foi a propulsora das transformações ocorridas não só no campo econômico, mas também nos campos políticos, religioso, educacional e de Saúde.

Em conseqüência observaram-se mudanças significativas e reorganização das profissões com a divisão de alguma delas, entre as quais a enfermagem, estabelecendo-se as categorias profissionais e ocupacionais, a distribuição de trabalhos entre os diferentes tipos de ocupação, instituindo-se hierarquização dos trabalhadores. Com este Modelo de hierarquização estabeleceu-se na enfermagem um corpo de trabalhadores, menos hábeis, conduzindo a passagem de poucas enfermeiras para posição de supervisão com a finalidade de controle do trabalho dos subalternos.

No entanto a divisão de trabalho parecia aos profissionais da época uma tendência lógica do ponto de vista dos princípios clássicos de administração, representando uma nova cadeia de comando. A enfermeira graduada foi colocada numa posição de responsabilidade pela supervisão das ações dos outros elementos do serviço.

Nessas circunstâncias a enfermeira passa a aceitar o fato de deixar que o pessoal ocupacional participe das atividades diretamente relacionadas com o cuidado do doente.

Neste contexto o paciente se constitui no centro das atividades e, assim sendo, as funções da equipe de enfermagem são ditadas pelo paciente de acordo com suas necessidades: desta maneira, as normas e rotinas são elaboradas de conformidade com o tipo e com a qualidade da assistência que o pessoal de enfermagem pretende oferecer.

Este modelo de assistência enfatiza a posição da enfermeira como líder da equipe, cuja responsabilidade reside na administração da assistência a um grupo de pacientes e na assistência propriamente dita: contudo ela delega certas atribuições da assistência aos membros da equipe, tomando só para sai a responsabilidade pelo 
planejamento, coordenação e supervisão da assistência.

O próprio relato da Comissão de Peritos da OMS, Londres 1955, ressaltava que em certas ocasiões, a enfermeira pode ser obrigada a desempenhar funções que, em geral, são da competência de outros profissionais da equipe médica.

Noutras ocasiões, a enfermeira pode delegar algumas de suas funções a membros menos qualificados do pessoal de enfermagem "... são as necessidades do doente e as limitações dos serviços existentes que determinarão a delegação ou o exercício das funções...".

Em 1955, em discurso proferido na qualidade de presidente da HABENA, Marina de Andrade Rezende expressa grande preocupação não só em termos de quantidade, mas também da qualidade dos enfermeiros formados “... as escolas não estão formando enfermeiras com capacidade de liderança de que necessitamos; não estão com poucas exceções, preparando seu pessoal para as funções de administração, ensino e supervisão, que irão exceder".

O número de enfermarias na década de 50 não ultrapassava 3500 (três mil e quinhentos) sendo que apenas 3000 (três mil) encontravam-se na ativa, enquanto apenas cerca de 2000 (dois mil) trabalhavam em hospital geral. Estimava-se a necessidade de 24000 (vinte e quatro mil) enfermeiras, além de 40000 (quarenta mil) pessoal de enfermagem. (PEDROSO, 1955)

Ainda em 1955, PEDROSO chega a triste conclusão de que "não existe enfermagem nos hospitais brasileiros salvo raríssimas exceções e em hospitais escolas, sendo que nos pouquíssimos hospitais que possuem enfermeiras, estas são as primeiras a atestar a deficiência do trabalho de enfermagem, seja por déficit numérico de pessoal e falta de equipamento e instalações adequadas". Na realidade os bons hospitais da década de 50 se constituem infelizmente uma minoria.

De maneira geral, o cuidado de enfermagem prestado no hospital se limitava, com poucas exceções, atender, principalmente, as necessidades básicas do paciente, isto é a higiene, a terapêutica, cuidados estes realizados por atendentes e alguns auxiliares de enfermagem sob a direção de uma enfermeira.

No $8^{\circ}$ Congresso Nacional de Enfermagem realizado em 1955 as enfermeiras reunidas comentam que "... Poucas enfermeiras dão cuidados diretos ao paciente, muitas executam atividades que poderiam ser delegadas a outros servidores". Em algumas localidades, notadamente do interior são-lhes delegadas responsabilidades que caberiam apenas aos médicos, tais como, anestesias, prescrição de entorpecentes, transfusão de sangue, provas de laboratório etc. As enfermeiras por falta de pessoal adequado são muitas vezes, obrigadas a desempenhar funções burocráticas".

Naquela oportunidade as enfermeiras manifestaram opinião de que as colegas devessem libertar-se das atividades estranhas às suas verdadeiras funções, passando a se dedicar mais ao paciente.

Nesta década, observa-se ainda um rápido desenvolvimento nos campos 
médico e técnico, ocasionando um aumento na demanda de equipamentos complexos por parte dos hospitais e, provavelmente, uma maximização de interesses pela segurança do paciente que resultou na criação de unidades especializadas. Conseqüentemente, houve uma inovação na prestação de cuidados, culminando com conhecimento e habilidades especiais.

Á enfermagem é estimulada a buscar conhecimentos novos buscando uma fundamentação teórica de base científica para o desenvolvimento de seus procedimentos técnicos.

O conceito de enfermagem hospitalar evolui consideravelmente. $O$ progresso da ciência e da técnica modificou a estrutura da organização hospitalar, traçando novos rumos para a enfermagem.

Ainda nesta década, acena-se para o esforço de líderes da enfermagem preocupadas em acompanhar a evolução do conhecimento médico, buscando implementar o uso do enfoque preventivo nas atividades hospitalares.

ALCÂNTARA et al (1955) afirmam ser difícil separar as atividades da enfermagem curativo das preventivas, uma vez que, na pratica estão muito associada. Essas autoras alertavam que "o hospital tinha sido destinado a cura, ou alívio da doença, estando todas suas atividades orientadas no enfoque curativo"; "... Hoje em dia, afirmavam elas, graças ao processo da medicina que dispõe de meios para o diagnóstico precoce de muitas doenças de desenvolvimento da medicina preventiva e psicossomática, das ciências sociais, o hospital pode ser considerado como um verdadeiro serviço de saúde pública, um centro de saúde da Coletividade. As líderes da enfermagem acrescentam", "se quisermos que os serviços de enfermagem em nossos hospitais não se distanciem do ritmo progressivo das Ciências Médicas e Sociais, é preciso dar ao cuidado de enfermagem direção nova".

Segundo PINHEIRO (1955) a enfermagem da década de 50 reconhecia que o serviço de enfermagem no Brasil era deficiente. Afirmava que esses serviços ressentiam de males de toda ordem dos quais um dos mais sérios era a falta de preparo do profissional. Propunha para sanar esta deficiência, programas de educação em serviço, entendendo este como o ensino oferecido ao servidor no contexto da própria instituição, dentro das horas de trabalho, com o intuito de melhorar a qualidade do serviço.

Apreende-se ainda pelas referências anteriormente citadas que para melhoria da qualidade dos cuidados de enfermagem nos hospitais, era preciso que as escolas dessem novas orientações aos seus currículos, integrando os aspectos sociais e de saúde desde o início do curso, ampliando os programas das Ciências Sociais e preparando as futuras enfermeiras para se ajustarem às rápidas mudanças sociais, dando-Ihes oportunidades para a prática da enfermagem preventiva. 


\title{
OBJETIVO
}

\author{
Partindo deste referencial histórico nos propusemos: a) resgatar a evolução \\ da assistência de enfermagem da década de 50; b) complementar os registros \\ existentes, através da memória viva destes profissionais.
}

\section{METODOLOGIA}

Embora haja especificações em termos de vivências à nível de região e tipo de hospital onde essas ocorreram (particular, estatal de ensino), optou-se no presente estudo pela investigação em um hospital escola do interior paulista, limitando a população aos 3 (três) enfermeiros representantes da década de 50, em exercício no Hospital em questão, disponíveis no período estipulado para o estudo, acrescido de mais 02 (dois) enfermeiros da referida década, aposentados, que manifestaram interesse em contribuir com o estudo.

Para tanto, utilizamo-nos da técnica oral, cujo termo amplo recobre uma quantidade de relatos a respeito de fatos não registrados por outro tipo de documentação, ou cuja documentação se queira complementar (QUEIROZ, 1988).

Colhido por meios de entrevista de várias formas esta técnica registra a experiência de um só indivíduo (enquanto representante de uma coletividade) ou de vários indivíduos da mesma coletividade.

A técnica utilizada envolve a modalidade de depoimentos pessoais, tendo esta formas especificas de agir do pesquisador. Da vida de informante só interessam os acontecimentos que venham se inserir diretamente no contexto do trabalho. Conhecendo o problema ou a temática a ser focalizada, buscou-se obter do narrador o essencial, dispensando o que é supérfluo e desnecessário para a análise dos dados. O pesquisador tem sob seu controle o enfoque do depoimento através de estratégias impregnas durante as entrevista (no caso da presente investigação, um roteiro, préelaborado avaliado por 3 juizes e testado em plano piloto) e direciona o depoimento para aspectos relevantes e significativos para a compreensão da temática a ser focalizada.

Mesmo o que o pesquisador venha registrar um número reduzido de depoimento, seu objetivo é captar a idéia do grupo, a sociedade da qual ele é parte. Busca, portanto, captar a coletividade a partir dos indivíduos. Não se trata de considerá-los isoladamente, nem de compreendê-los em sua individualidade, ao contrário o que se pretende é captar, através de seus depoimentos, o que se passa no interior das coletividades da qual participam ou são membros integrantes. Os 
sujeitos não são individualizados, eles agora são pessoas representativas, não sendo nem mesmo necessários nominá-los. Todavia, em seus anonimatos esses indivíduos contém um microcosmo as configurações que sua coletividade abarca, ao ordenar umas em relações às outras unidades, de que se compõem o grupo.

Corroborando as idéias de que a quantidade não significa necessariamente qualidade, temos o pensamento de DURKHEIM (1960), para qual “... não é a quantidade de fatos registrados que conduz a conhecimentos novos e sim, a análise cuidadosa de fatos decisivos e cruciais".

\section{PROCEDIMENTO}

Inicialmente foi dado aos sujeitos a liberdade de exporem sua vivências, através de relato, a partir da formulação de duas questões norteadoras. "Como era a assistência de Enfermagem na década de 50?"; "Como é ou está a Enfermagem hoje?". Após o relato foi oferecido ao enfermeiro um roteiro a ser consultado para complementação de seu depoimento, cujo objetivo foi tentar a abrangência da temática e homogeneização do conteúdo dos depoimentos. Segundo a preferência, o relato foi feito por escrito, pelos próprios sujeitos, em local e tempo determinado, de acordo com suas disponibilidades.

Com base no registro dos depoimentos, realizou-se a análise dos conteúdos para o qual utilizou-se o Modelo de Categorização de GIORGI (1985) adaptado para o presente estudo.

Este procedimento propiciou uma retomada no contato com o conteúdo dos depoimentos favorecendo um procedimento de análise em maior profundidade.

Para tal seguiu-se os seguintes passos:

- leitura atentiva do conteúdo total dos depoimentos com vistas a apreensão do seu significado na estrutura global;

- relicitar de cada depoimento e procedimento de cores nos relatos, tendo por base, em $1^{\circ}$ (primeiro) lugar, temas mais amplos e em seguida temas específicos relevantes para a compreensão e análise de temática em questão;

- agrupamento destes recortes em categorias visando a identificação de pontos comuns nos três depoimentos na ordem dos questionamentos de maior inquietação;

- análise compreensiva destes agrupamentos tendo em vista o objetivo maior: resgate da evolução da Enfermagem e sua atuação na década de 50.

\section{ANÁLISE E COMENTÁRIOS DOS DEPOIMENTOS}

Os depoimentos evidenciaram que na década de 50, os sujeitos (enfermeiros) sentiam-se de certa forma desprestigiados enquanto a profissão era pouco conhecida e divulgada. 


\section{enfermagem..." \\ “... sentíamos a necessidade de explicar sempre a finalidade da}

As jovens candidatas à Enfermagem da década de 50, tinham dificuldade em convencer seus familiares a aceitarem sua opção profissional, sendo que, muitas tiveram que lutar contra preconceitos para realização de seus idéias.

“... era difícil até para os familiares entenderem o porquê tínhamos optado por esta profissão..."

A Enfermagem da década de 50, dado o fato de encontrar-se ainda (no Brasil), numa fase de transição para o status de nível universitário, não tinha ainda conquistado o crédito de outros profissionais.

“... tínhamos que nos impor para conquistar a confiança e o respeito dos demais profissionais..."

“... com as outras profissões era diferente... a enfermagem por ser uma profissão predominante feminina era desconsiderada..."

Estes depoimentos reforçam as conclusões emitidas pela Organização Mundial da Saúde (1954) que afirmava em seu $3^{\circ}$ Relatório da Comissão de Peritos em Enfermagem que o status de enfermagem era problema desde os dias mais remotos da sua história. Padrões culturais proibiam à mulher a liberdade necessária, tanto para instrução quanto para prática de uma profissão. Afirmava ainda que naquela década (50), na maioria dos países, ainda não era dada a enfermeira instrução suficiente para colocá-la à altura de outros profissionais liberais. O referido relatório opinava que o problema só seria resolvido quando o ensino da enfermagem repousasse sobre bases sólidas, comparável à dos outros profissionais do campo da saúde.

$\mathrm{Na}$ realidade foi na década de 50 , que começou a surgir a preocupação em organizar os princípios científicos que deveriam nortear a prática da enfermagem brasileira. Até então a enfermagem era vista como não científica e suas ações baseadas na situação.

Segundo SMITH (1953), para que a educação em enfermagem chegasse a ser uma necessidade social de responsabilidade pública tornava-se indispensável uma mudança de pessoas em geral, em relação à profissão. Segundo a autora, os leigos possuíam uma concepção errônea das escolas de enfermagem, pensando que estas continuavam a ensinar os estudantes como se fossem aprendizes. Esta desinformação levava o leigo a não distinguir as categorias do pessoal não diferenciado, da enfermeira diplomada, chamando de enfermeira qualquer pessoa que se apresentasse de avental banco.

Confirmou-se, pelos depoimentos, que as enfermeiras do hospital escola em estudo eram, na década de 50 , membros da equipe de saúde e entre suas dificuldades no desempenho deste papel, estava a de relacionamento e entrosamento com os médicos e também o fato de terem suas atribuições ampliadas, tendo que conciliar suas responsabilidades de líderes da equipe de enfermagem, membros da equipe de saúde e cuidado direto ao paciente. 
Assumir dois papéis opostos: passar de subordinado a líder dentre de um mesmo contexto parece ter sido um processo radical e traumático.

“... Nós assumíamos tudo... com muita subordinação”.

Fica claro que o despreparo do trabalho em equipe não era uma deficiência exclusiva do enfermeiro, mas de todos os profissionais envolvidos ao novo sistema implantado.

“... Havia dificuldades na interação entre médicos e enfermeiras...”.

Pelos relatos identifica-se sentimentos de medo, de perdas, inseguranças e ambivalências peculiares a situações de transição.

“... enquanto membro da equipe tínhamos um relacionamento profissional muito rígido e formal...".

Detecta-se um certo conflito entre comandar e ser comandado; aceitar subordinação e exigir subordinação; liderar e ser liderado.

“... tínhamos os atendentes e os auxiliares subordinados a nós... ora éramos subordinados ora subordinávamos...".

“... tínhamos a competência, mas faltava-nos autoridade".

Esta dificuldade segundo dados apreendidos na literatura disponível, era o reflexo do tipo de organização e tendências administrativas baseadas na estrutura hierárquica que se manteve no hospital ainda pela influência e persistência do Modelo Funcionalista, muito presente naquela década.

Em artigo publicado na década de 50 , estas dificuldades foram previstas e assim expressas “... o processo de equipe consome tempo até os membros aprenderem a usá-lo. Poderão surgir tensões sérias que determinarão o colapso da equipe caso o modelo não seja usado com confiança". Dessa forma um bom trabalho de equipe dependia da harmonia das relações humanas. Era, portanto, preconizado a compreensão e o apreço mútuo entre os membros da equipe. (Comissão de Peritos em Enfermagem, OMS 1955).

Fica claro que a enfermagem no contexto do Hospital Escola estudado, começava conquistar o respeito e reconhecimento pela sua competência.

“... eu participava realmente da equipe de saúde e era respeitada como profissional membro desta equipe... eu era requisitada a acompanhar as visitas médicas e a opinar sobre o estado do paciente...".

“... A enfermeira antigamente tinha total poder sobre tudo o que acontecia na sua área desde a admissão até a alta do doente e havia uma equipe médica também muita boa".

Segundo os relatos havia uma preocupação por parte da enfermeira em não se afastar do cuidado direto ao paciente. Percebe-se uma certa satisfação e orgulho em assumir a responsabilidade pela liderança da equipe e responsabilidade pelo cuidado ao paciente.

“... realmente me sentia enfermeira padrão, era responsável pela equipe de enfermagem e pelos pacientes sob meus cuidados...".

"... Era um trabalho exaustivo, mas gratificante porque se fazia todas as funções: psicologia, assistente social, fisioterapia, etc...". 


\section{outras...".}

“... Com o tempo a enfermeira foi perdendo funções e não assumiu

“... Algumas áreas, como o ambulatório, colocaram outras atividades: orientação individual; consulta de enfermagem; teste de penicilina; triagem de enfermagem; trabalhos científicos; etc...".

O relacionamento enfermeiro-paciente se revela ponto de honra para os profissionais de campo da década de 50 e fator de críticas severas à situação dos enfermeiros atuais.

“... quanto ao relacionamento enfermeira-paciente, tínhamos melhor interação que hoje...".

Esta deficiência é sentida pelos enfermeiros da década de 50 como uma das contradições da Enfermagem atual.

“... no entanto, a enfermeira de hoje está mais apta para fazer parte da equipe de saúde e deveria ter um melhor relacionamento com o paciente".

Estas contradições se afiguram de certa forma incompreensíveis pelos sujeitos, dado as condições de maior oportunidade de preparo das enfermeiras atuais.

“... hoje, embora não estando participando ativamente como membro da equipe de saúde do hospital, percebo que algo mudou, e, mudou para pior”.

Nestas reflexões insurgem questionamentos reveladores de dúvidas, incertezas e inquietações.

“... o que será que está acontecendo com a enfermeira padrão? Será que a sua formação não Ihe oferece condições seguras para assumir sua função de liderança na equipe?...".

Segundo opinião expressa pelos sujeitos em seus depoimentos, a enfermeira da década de 50, embora sem o preparo devido ou ainda, menos preparado, correspondia mais às funções de liderança do que as enfermeiras atuais.

“... atualmente observo, uma grande preocupação com a organização, parte burocrática, títulos, escalas hierárquicas... mas não uma postura de liderança...".

Os sujeitos expressam algumas críticas relacionadas ao distanciamento da enfermeira atual com o paciente.

“... a assistência e o diálogo com o paciente deveria ser mais constante".

Embora depreenda-se dos depoimentos uma certa capacidade de adaptação e disposição da enfermeira em assumir as atividades administrativas e/ou burocráticas fica claro o seu despreparo e o esforço suplementar das enfermeiras da década de 50 , para exercê-las.

ALMEIDA (1953), em trabalho apresentado no X Congresso Brasileiro de Higiene, afirmava que as enfermeiras ao deixarem as escolas de enfermagem, 0 faziam com duas deficiências importantes, desconhecimento quase completo de enfermagem de Saúde Pública e de administração de enfermagem.

Por outro lado, segundo os depoimentos os cursos de enfermagem da década de 50, privilegiaram uma formação voltada para prática. As técnicas eram bastante 
enfatizadas e exigia-se além da competência também as habilidades manuais, a destreza e o correto manuseio das técnicas.

Os sujeitos manuseiam a consciência da necessidade do equilíbrio entre teoria e prática e uma certa insatisfação pelo predomínio e maior valorização da teoria na formação acadêmica do enfermeiro atual.

“... nos cursos de enfermagem (na década de 50) a orientação acadêmica era volta mais para a prática que para a teoria...".

Apreende-se um certo posicionamento crítico desses profissionais, pela deficiência na formação prática dos enfermeiros atuais atribuída às Escolas de Enfermagem.

“... hoje vejo a orientação acadêmica direcionada mais para a teoria que para a prática...".

Os depoimentos revelam ser do entendimento das enfermeiras da década de 50 , a necessidade de privilegiar a prática em detrimento da teoria.

“... ambas se completam, mas na enfermagem, a prática no meu entender, deve se sobressair...".

Está na presente na memória dos sujeitos pesquisados (a consciência dos) os efeitos das rápidas e profundas transformações tecnológicas no âmbito hospitalar. Fica clara, a necessidade de adaptações advindas desta evolução e conseqüente complexidade para prática da enfermagem, porém também os aspectos positivos destas mudanças para o desenvolvimento da profissão, sobre tudo os esforços realizados pela enfermeira para acompanhar esse processo. Presente esta também o reconhecimento da necessidade da pesquisa na área, bem como a importância do conhecimento científico.

“... até então o domínio nas rotinas era o que nos dava segurança...".

“... havia muita preocupação em se cumprir e fazer cumprir todas as rotinas...".

Segundo PINHEIRO (1955), uma das características principais da profissão da enfermagem até a década de 50 era o conservantismo e o gosto pelas rotinas estabelecidas e como decorrência a não aceitação das coisas novas. rápidas...".

“... as transformações tecnológicas trouxeram mudanças muito

O fato de estas transformações afetarem as rotinas, marcou um clima temporário de desestruturação dos serviços com reflexo no desempenho dos profissionais de Enfermagem.

“... mudou muitas rotinas trazendo certa insegurança”.

"... Ao longo do tempo estabeleceram-se rotinas que acabaram tendo mais valor que o doente... é assim, porque é a rotina...".

No entanto, nota-se, pelos depoimentos a conscientização da necessidade e esforço de adaptação com manifestações de disposição, iniciativa e empenho.

“... cada nova técnica era sempre um novo desafio, mas, também uma aquisição de novos conhecimentos...". 
“... para acompanhar a evolução foi necessário estudar e trabalhar junto com a equipe...".

“... minha adaptação se deu através de estudo de atualização promovidos pela escola e nos grupos de trabalho e principalmente em estudos junto a equipe."

Os sujeitos mencionam como fator significativo para a qualidade da assistência prestada na década de 50, o estreito relacionamento da escola com o hospital e uma insatisfação em relação à não solidificação deste vínculo e buscam explicações que justifiquem deste distanciamento.

“... Naquela época as professoras eram chefes da enfermagem e as enfermeiras tinham total apoio destas professoras, elas trabalhavam muito, eram excelentes profissionais e colaboravam com o hospital...".

“... Não havia tanta preocupação com teses, com publicações, elas se preocupavam mais com os doentes e com o ensino...".

“... A escola foi se afastando do hospital, talvez pelas exigências da carreira universitária e isso foi muito ruim para a profissão...".

“... Os docentes da escola, antes muito ligados ao hospital foram se afastando e perderam o espaço...".

Percebe-se que as enfermeiras pesquisadas através do contato com os docentes, alunos e Escola, puderam reconhecer a importância e necessidade da investigação de Enfermagem para melhoria da assistência, embora este reconhecimento tende-se se traduzir numa aspiração e busca de status.

“... a evolução tecnológica e a pesquisa trouxeram melhoria no conceito da enfermagem dando maior reconhecimento, satisfação e status para este profissional...".

“... a enfermagem passou por uma evolução tecnológica e isso tem sido muito bom...".

Havia uma certa preocupação em definir o trabalho de enfermagem dando a ele uma conotação mais intelectualizada e a pesquisa veio de encontro a este anseio de obter status na equipe reconhecimento por parte da sociedade.

“... nosso trabalho era manual embora fundamentado e em princípios científicos aprendidos na escola...".

“... o curso que eu tive foi maravilhoso tendo um respeito muito grande pelas minhas professoras: Dra . Glete, Maria de Lourdes Vadala, Judithe Costa, Circe e Orlis...".

“... as docentes foram pessoas fantásticas e se preocuparam com a formação integral do enfermeiro (curso de inglês, literatura, etc.)... eram criaturas adoráveis, e tinham visão universitária...".

"... o ensino profissional eu acho que era muito bom, o aluno era bem preparado para enfrentar e assumir os encargos profissionais...".

“... hoje a escola perdeu muito desta dimensão que era avançadíssima para a época...". 
"... desde alunos aprendíamos a improvisar materiais e a executar técnicas alternativas para atender as necessidades específicas dos doentes...".

“... com o passar do tempo fui percebendo que o rigor de exigências foi diminuindo e a enfermagem não conseguiu achar um meio termo...". deterioração...".

“... a postura profissional, principalmente, sofreu uma grande

Em artigos publicados na década de 50, constamos haver neste sentido uma luta das lideranças de enfermagem manifestada pela afirmação de que nem a enfermagem nem o público que ela servia tinha consciência do seu valor como força social na vida moderna. Entretanto, afirmavam que a sociedade chegaria a compreender o valor da profissão de enfermagem bem como sua grande responsabilidade em relação a melhoria das condições que afetam a saúde, da mesma forma que atuam o alívio da dor e desajustamos causados por essas mesmas condições. Por outro lado sabia-se que a enfermagem, em outros países, como nos Estados Unidos, a Dinamarca, a Suécia e a Inglaterra estavam alcançando a sua maturidade científica.

Houve ainda, na década de 50, segundo depoimentos dos sujeitos, uma grande valorização dos aspectos éticos e morais para a formação dos profissionais enfermeiros na escola freqüentada pelo sujeitos da pesquisa.

“... os valores éticos e morais, postura correta e responsabilidade eram extremamente valorizados como imprescindíveis para a formação da enfermeira..."

"... a escola de enfermagem primava pela formação ética e moral do enfermeiro e era muito exigente nesse aspecto com os alunos".

“... na minha época o ensino era rigoroso e levado a sério... a disciplina era como numa escola militar em relação à obediência às normas e ao comportamento e vestuário...".

“... a ética foi enfraquecida, saímos de um rigor absoluto para a permissividade...".

É da década de 50, o Código Internacional de Ética em Enfermagem adotado no Brasil, em 17 de outubro de 1953, após aprovação em assembléia geral da HABENA em Recife.

\section{CONSIDERAÇÕES FINAIS}

Pelos depoimentos constata-se que a enfermeira da década de 50 sentia-se desprestigiada tanto em nível da sociedade quanto da equipe médica enquanto a profissão era pouco reconhecida. As jovens candidatas a enfermagem quando 
vocacionadas tinham que lutar contra preconceitos para realização de seu ideal. As enfermeiras sentiam ainda o peso da desvalorização da mulher na sociedade interferindo no desenvolvimento do seu status profissional.

A década de 50 foi marcada por grandes e profundas mudanças no setor Saúde e particularmente na prática de enfermagem. A reorganização das profissões estabeleceu a divisão de categorias profissionais instituindo a hierarquização dos trabalhadores desta área. A enfermagem assumiu a responsabilidade pelo planejamento, coordenação e supervisão e da assistência, delegando certas atribuições aos seus auxiliares. Embora sem preparo adequado a enfermeira dos anos 50 assumiu as atividades administrativas desempenhando o papel de liderança da equipe de enfermagem e membro da equipe de Saúde. Embora, nesta época, o serviço de enfermagem fosse, de modo geral, deficiente do Brasil, o Hospital-Escola estudado foi cenário de significativa evolução para a enfermagem, oferecendo para aos profissionais, condições para o desenvolvimento de suas competências, (fruto de sua formação sólida). Se por um lado, a enfermeira detinha o conhecimento e a habilidade, por outro, faltavaIhe autoridade. Embora segura no manejo das rotinas, a enfermeira, da década de 50, já reconhecia a importância e o valor do conhecimento científico para o desenvolvimento da profissão.

Os depoimentos mostram o esforço e a dedicação do profissional enfermeiro, daquela década, pela conquista e reconhecimento de seu valor perante a equipe médica, e o compromisso em cumprir de forma rigorosa as atribuições a ela designadas.

Destaca-se ainda nos depoimentos a relevância dos valores e atitudes éticas subvalorizadas pelas influências no momento histórico importante, ou seja, a adoção do Código Internacional de Ética em Enfermagem, (adotado no Brasil na década de 50 e pela exigência das Escolas em relação a estes valores, na formação do enfermeiro.

\section{CONCLUSÃO}

Apreende-se que a assistência hospitalar da década de 50 se deu com base na competência, na ética e no compromisso do profissional enfermeiro. O profissional lutou pela conquista de seu espaço assumindo com responsabilidade e liderança o cuidado de enfermagem. Embora enfrentando sérios conflitos num contexto de ambigüidades, teve sua presença confirmada e reconhecida pela equipe médica. 


\section{OBTAINING PERSONAL DECLARATIONS OF HOSPITAL NURSES THAT ACTUATED IN THE 1950's: ELEMENTS TO NURSING COMPREHENSION}

This study is a part of a more extensive project that proposes to rescue significant aspects related to nursing assistance evolution from the 1950's to the 1990's. Aiming at accomplishing this objective, the authors used the technique of oral declaration with active and retired registered nurses, in the context of a school-hospital at the state of São Paulo. The present study emphasizes the outcomes referring to the 1950's. The results shows that nurses' effort are evident in the struggle for profession's recognition and prestige; there are intense and deep transformations related to nurse's new roles and leadership as a member of the nursing staff and a member of the medical team.

UNITERMS: nursing evolution, 1950's, hospital assistance

\section{DECLARACIÓN PERSONAL DE ENFERMERAS HOSPITALARIAS DE LA DÉCADA DEL 50: COMO AYUDA PARA LA COMPRENSIÓN DE LA ENFERMERÍA ACTUAL}

El estudio es parte de un proyecto más tendiente a la captación de aspectos significativos relacionados a la evaluación de asistencia de enfermería en las décadas de 50 a 90. La captación se ha realizado a través de la técnica de declaraciones orales de los enfermeros en ejercicio de la profesión y jubilados, en el contexto de un Hospital Escuela del Interior del Estado de São Paulo. El presente estudio particulariza los resultados obtenidos, referentes a la década del 50. Como resultados se evidencian el esfuerzo impreso por las enfermeras en la lucha por el reconocimiento y prestigio de la profesión. Las transformaciones intensas y profundas relacionadas a los nuevos roles de la enfermera como líder de los trabajadores de enfermería y miembro del grupo de la Salud.

UNITERMOS: evaluación de la asistencia, década del 50, asistencia hospitalaria

\section{REFERÊNCIAS BIBLIOGRÁFICAS}

01. ALCÂNTARA, G., VALLADA, M., RIBEIRO, C.M. Aspectos preventivos da Enfermagem hospitalar. Rev. Bras. Enfermagem, Rio de Janeiro, v. 8, n. 3, p. 200-2, setembro 1955. 
02. ALMEIDA, A.J. de. Integração do hospital no plano geral de Saúde Pública, em áreas rurais. Anais Enfermagem, Rio de Janeiro, v. 4, n. 3, p. 202-10, setembro de 1953.

03. CONGRESSO NACIONAL DE ENFERMAGEM, 8. Notícias e Comentários/apud Rev. Bras. Enfermagem, v. 8, n. 3, p. 69, setembro de 1955.

04. DOURADO, H.G. Código Internacional de Ética de Enfermagem/Editorial/. Anais Enfermagem, Rio de Janeiro, v. 4, n. 3, p. 4, setembro 1953.

05. DURKHEIM, E. As regras do método sociólogo. 2 ed.. São Paulo: Nacional, 1960. p. 74,5

06. ENFERMAGEM, seu preparo e seu papel nos programas de saúde. Rev. Bras. Enfermagem, São Paulo, v. 8, n. 3, p. 173, setembro 1955. I Apresenta no XIII Congresso de Enfermagem, São Paulo, 1955./

07. FORJAZ, M.V. de. O aspecto social da enfermagem. Rev. Bras. Enfermagem, Rio de Janeiro, v. 8, n. 2, p. 127-46, junho de 1955.

08. GIORGI, A. Phenomenology and psycological research. Pittsburg: Duchesne, Unversity, 1985.

09. ORGANIZAÇÃO MUNDIAL DE SAÚDE. Comissão de peritos. Terceiro relatório. Rev. Bras. Enfermagem, v. 8, n. 1, p. 17-51, março 1955.

10. ORGANIZAÇÃO MUNDIAL DA SAÚDE. Terceiro relatório da comissão de peritos em Enfermagem. Rev. Bras. Enfermagem, Rio de Janeiro, v. 8, n. 1, p. 17, março de 1955.

11. PEDROSO, O.P. O papel da enfermagem no programa de assistência médico hospitalar. Rev. Bras. Enfermagem, Rio de Janeiro, v. 8, n. 3, p. 215-18, setembro 1955.

12. PINHEIRO, M.R, Educação em serviço. Rev. Bras. Enfermagem, Rio de Janeiro, v. 8, n. 3, p. 257-58, setembro de 1955.

13. QUEIROZ, M.I.P. Relatos orais: do "indizível ao dizível", In: VON SIMSON, O.M. (org.). Experimentos com história de vida: Itália-Brasil. São Paulo: Vértice, 1988, p. 14-43.

14. SMITH. C.E. O ensino da enfermagem: uma responsabilidade pública. Nursing Outlook, v. 1, n. 2, fevereiro, 1953, p. 96-7. apud. Rev. Bras. Enfermagem, v. 8, n. 1, março 1955, p. 60-5. 